\title{
Familial adenomatous polyposis
}

\begin{abstract}
Familial adenomatous polyposis (FAP) is autosomal dominant inherited disorder. Usually there are more than 100 polyps. All can develop carcinoma of the colon if not treated. Median life expectancy is 42 years in untreated and this can be extended greatly if colectomy is performed. Causes of death after colectomy are upper GI cancers and desmoids. Family members should be informed about screening. Carcinoma surveillance is essential after colectomy.
\end{abstract}

Keywords: autosomal, colectomy, cancers, genetic defect, diseases
Volume 3 Issue I - 2017

\section{Joshi BR}

Department of Radiology, Tribhuvan University Teaching Hospital, Nepal

Correspondence: Joshi BR, Department of Radiology, Tribhuvan University Teaching Hospital, Nepal, Emailbjoshi0I@yahoo.com

Received: September 23, 2016 | Published: May 25, 2017
Abbraviations: FAP, familial adenomatous polyposis; AAPC, adenomatous polyposis coli; DNA, deoxyribonucleic acid; CT, computed tomography; HRE, high-resolution endoscopy; FICE, fujinon intelligent color enhancement; NBI, narrow-band imaging

\section{Introduction}

Familial adenomatous polyposis (FAP) is autosomal dominant inherited disorder. Usually there are more than 100 polyps. All can develop carcinoma of the colon if not treated. The genetic defect gives rise to phenotypic spectrum of diseases such as FAP, Gardner's syndrome, Turcot's syndrome, attenuated adenomatous polyposis coli (AAPC) etc.

\section{Case report}

A female of 37years presented with per rectal bleeding for 8years to the Department of Radiology of Tribhuvan University Teaching Hospital in 2007 for a barium enema study. Her elder brother had similar symptoms and he had undergone colectomy. Her late father also suffered from recurrent episodes of per rectal bleeding. Two big brothers died in childhood. Her sister had also died of distension of abdomen. She has two children who are asymptomatic. Her double contrast barium enema study shows multiple round filling defects involving the whole colon including the rectum (Figure 1). Barium study of her brother showed irregular large filling defect in the rectum due to malignant mass in addition to multiple small filling defects (Figure 2).

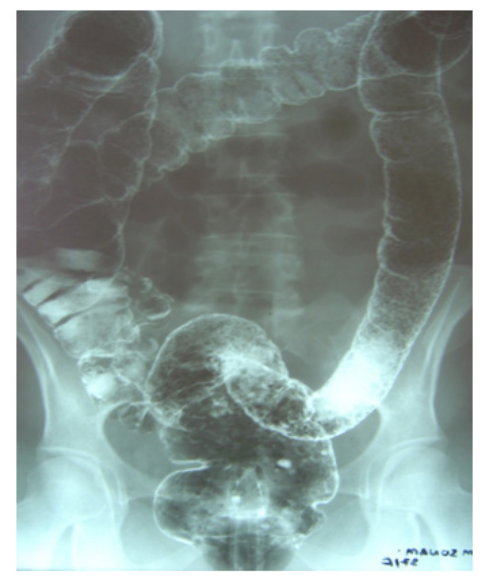

Figure I Double contrast barium enema study of the patient.

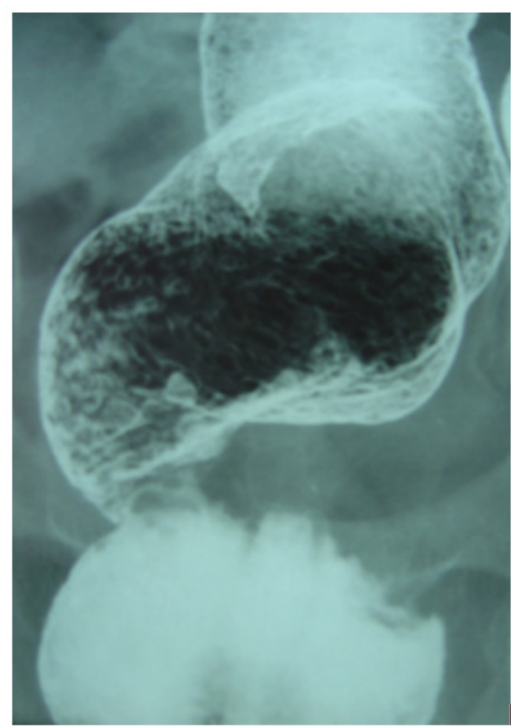

Figure 2 Barium study of the patients' brother showed irregular large filling defect in the rectum due to malignant mass in addition to multiple small filling defects.

\section{Discussion}

Adenomatous polyposis coli (APC) gene is located in the long arm of chromosome 5. APC protein promotes apoptosis of b-catenin. B-catenin inactivate APC gene. Every colonic epithelial cell has one mutated and one normal copy of APC. Inactivation of normal copy occurs by deletion or mutation. Increase in b-catenin completely removes tumour suppressive function.

The frequency of this disease is between 1:7000-31000. All races are vulnerable. Sex incidence is 1:1. Age of onset is 16years (36years in AAPC). The patients are often asymptomatic. They may develop desmoid, adenocarcinoma of duodenum or papilla after colectomy. In patients who develop colorectal carcinoma, a $100 \%$ mortality is observed. The onset of carcinoma is 39years (54years in AAPC). Family history may not be present in $25 \%$. Usually there is family history of polyp or colorectal carcinoma at 40years or younger. The young patient may suffer from unexplained rectal bleeding, diarrhea, abdominal pain. Some may be asymptomatic until they develop carcinoma. ${ }^{1}$

On examination, congenital hypertrophy of retinal pigment 
epithelium, osteomas of skull and mandible, odontomas and dentigerous cyst, epidermoid cyst, fibromas, palpable abdominal \rectal mass may be present. Associated findings are adenomas of duodenum $(100 \%)$, harmatomatous polyps in stomach $(50 \%)$, desmoids $(12 \%)$, periampullary Carcinoma $(5 \%){ }^{2}$

Imaging studies used are flexible sigmoidoscopy, colonoscopy, gastroendoscopy, Barium studies, CT scan for desmoid, skull and dental $\mathrm{x}$-rays.Screening methods are ophthalmic examination, flexible sigmoidoscopy (1-2years from 12-35years; 3years thereafter); genetic testing- DNA markers with linkage analysis. Complications are colorectal carcinoma, duodenal periampulary adenocarcinoama, medullblastoma, hepatoblastoma, thyroid \& adrenal carcinoma, rectal carcinoma. Peri-ampullary tumours develop in $11 \%$ by the age of 50 years and $52 \%$ by the age of $75 .^{3}$

Median life expectancy is $42 y e a r s$ in untreated and this can be extended greatly if colectomy is performed. Family members should be informed about screening. Carcinoma surveillance is essential after colectomy. $^{3}$

Duodenal and periampullary cancer is the most common cause of cancer death in patients with familial adenomatous polyposis who have undergone colectomy. Endoscopic surveillance of upper gastrointestinal adenomas is recommended for patients with familial adenomatous polyposis. ${ }^{4}$ The prevalence of duodenal adenomatosis among FAP patients varies from $50 \%$ to greater than $90 \%$, while only few patients $(3-5 \%)$ develop duodenal cancer. Periampullary adenomas seem to carry a high risk of malignant transformation. The sensitivity of endoscopic procedures for early detection of severely dysplastic or malignant duodenal lesions is low, and the prognosis of duodenal cancer is poor. Thus the question arises whether it is possible to define a subgroup of high-risk patients for duodenal malignancy, and whether severe duodenal adenomatosis should lead to an aggressive prophylactic surgical approach. ${ }^{5}$

The Spigelman classification stratifies cancer risk in familial adenomatous polyposis (FAP) patients with duodenal adenomatosis. High-resolution endoscopy (HRE) and narrow-band imaging (NBI) may identify lesions at high risk. ${ }^{6}$ The fujinon intelligent color enhancement (FICE) significantly increases adenoma detection rate in FAP patients but does not change any Spigelman stage and thus does not modify patient's prognosis and treatment strategies. ${ }^{7}$

HRE has raised the quality of endoscopic imaging considerably. Consequently, re-evaluation of the original Spigelman classification system seems advisable. Chromoendoscopy further increases detection of duodenal adenomas in FAP but without considerable change in Spigelman stage. Ampullary adenomas are commonly found in FAP and are best visualized using a side-viewing endoscope. Therefore, a combination of forward-viewing HRE and chromoendoscopy with side-viewing endoscopy for the periampullary region seems useful for surveillance of duodenal adenomatosis in FAP. ${ }^{8}$
After staining a larger number of duodenal polyps were found than at the standard endoscopic examination, the difference being statistically significant. Chromoendoscopy may improve diagnostic yield of endoscopy. ${ }^{9}$ Jejunal adenomas in FAP patients are reported occasionally and can progress into adenocarcinoma with a poor prognosis. In the future a subset of FAP patients benefitting from jejunal surveillance should be identified. ${ }^{10}$ Clinically significant jejunal polyposis in FAP is rare, even in high-risk patients with advanced duodenal disease. ${ }^{11}$

\section{Acknowledgements}

None.

\section{Conflict of interest}

Author declares that there is no conflict of interest.

\section{References}

1. Brian T. The Colon. In: Sutton D, editors. Textbook of Radiology. 5th ed. London: Churchill Livingstone; 2013. p. 874-876.

2. Bastram CI. The Large Bowel. In: Grainger RG, editors. Diagnostic Radiology. 3rd ed. London: Churchill Livingstone; 2013. p. 1112-1113.

3. http://emedicine.medscape.com/article/175377-overview

4. Alarcon FJ, Burke CA, Church JM, et al. Familial adenomatous polyposis: efficacy of endoscopic and surgical treatment for advanced duodenal adenomas. Dis Colon Rectum. 1999;42(12):1533-1536.

5. Kadmon M, Tandara A, Herfarth C. Duodenal adenomatosis in familial adenomatous polyposis coli. Int J Colorectal Dis. 2001;16(2):63-75.

6. Lopez-Ceron M, van den Broek FJ, Mathus-Vliegen EM, et al. The role of high-resolution endoscopy and narrow-band imaging in the evaluation of upper GI neoplasia in familial adenomatous polyposis. Gastrointest Endosc. 2013;77(4):542-550.

7. Lami G, Galli A, Macrì G, et al. Gastric and duodenal polyps in familial adenomatous polyposis patients: Conventional endoscopy vs virtual chromoendoscopy (fujinon intelligent color enhancement) in dysplasia evaluation. World J Clin Oncol. 2017;8(2):168-177.

8. Dekker E, Boparai KS, Poley JW, et al. High resolution endoscopy and the additional value of chromoendoscopy in the evaluation of duodenal adenomatosis in patients with familial adenomatous polyposis. Endoscopy. 2009;41(8):666-669.

9. Picasso M, Filiberti R, Blanchi S, et al. The role of chromoendoscopy in the surveillance of the duodenum of patients with familial adenomatous polyposis. Dig Dis Sci. 2007;52(8):1906-1909.

10. Ruys AT, Alderlieste YA, Gouma DJ, et al. Jejunal cancer in patients with familial adenomatous polyposis. Clin Gastroenterol Hepatol. 2010;8(8):731-733.

11. Alderlieste YA, Rauws EA, Mathus-Vliegen EM, et al. Prospective enteroscopic evaluation of jejunal polyposis in patients with familial adenomatous polyposis and advanced duodenal polyposis. Fam Cancer. 2013;12(1):51-56. 